\title{
UMA ANÁLISE DA INDUMENTÁRIA EM MORTAL KOMBAT: HISTÓRICO E EVOLUÇÃO
}

Régis Puppim*

\begin{abstract}
RESUMO: O presente artigo procura analisar a evolução das imagens dos personagens de jogos eletrônicos, sobretudo em suas indumentárias, com estudo de caso em Mortal Kombat, nas suas versões 1, 2, 3, 4 e Armageddon, respectivamente lançadas em 1992, 1993, 1995, 1997 e 2006. Nesta iniciativa, tivemos a oportunidade de registrar a importância recreativa e cultural que os games exercem sobre na sociedade contemporaneamente. Além disso, demonstramos que as novas tecnologias e ferramentas desenvolvidas nos referidos jogos incorporam recentemente, com muita propriedade, alguns aspectos do comportamento humano referente ao vestir, fato que evidencia a preocupação dos criadores de jogos em atender e superar as expectativas daqueles que jogam, em relação às roupas que os personagens vestem. Ao longo do recorte temporal estudado, notamos que foram agregadas características de interatividade, melhorias de desenvoltura ao longo do jogo e de representação gráfica, princípios de design e maior funcionalidade, tornando o jogo cada vez mais sofisticado.
\end{abstract}

PALAVRAS-CHAVE: Mortal Kombat. Game design. Figurino. Design de aparência.

Enquanto para o teatro existem noções de criação de figurino desde a Grécia Antiga, nos teatros de arena, segundo MENDONÇA (2006), enquanto que para o videogame, os game designers vieram a preocupar-se apenas quando a tecnologia, que revoluciona cada vez mais os jogos, permitiu a utilização de recursos gráficos mais sofisticados.

Ao estudarmos a história do videogame, notamos que o pioneiro Ralph Bear criou, em 1951, a primeira "máquina de jogos" considerada um videogame, segundo WINTER ${ }^{1}$. Porém, sua popularização deu-se apenas em meados da década de 70, com a empresa ATARI disseminando os Arcades².

Os videogames portáteis, como conhecidos hoje, se massificaram no Brasil na virada da década de 80 para 90, sob as plataformas Nintendo e Mega Drive. Neste período, devemos destacar dois jogos que marcaram a geração de

\footnotetext{
*Universidade Federal de Goiás. Imeio: regispuppim@gmail.com.

${ }^{1}$ David Winter. Autor e editor do site Pong-Story.com.

${ }^{2}$ Chamados no Brasil de máquina de Fliperama
}

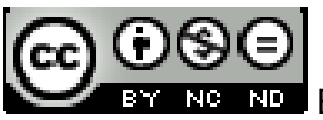

Texto Digital, Florianópolis, v. 8, n. 2, p. 196-223, jul./dez. 2012. ISSNe: 1807-9288 
crianças e adolescentes que jogavam videogame. Street Fighter II, lançado em 1991, tornou-se o jogo mais famoso da década de 90, por ter sido o mais vendido, tanto nas plataformas portáteis, quanto nos arcades, além do mais memorável para esta geração, segundo jornais e revistas especializadas da época, mesmo que seu antecessor, Street Fighter I, não fosse logrador de tantas glórias, por não pertencer ao gênero de luta, como sua vanguardista segunda versão. E Mortal Kombat - lançado em 1992, causou grande polêmica por sua explícita violência, chegando a levantar discussões no Senado Americano sobre seu possível banimento das lojas do país. Entretanto, com alto apelo popular do jogo entre os jovens, a polêmica resultou num projeto de lei que foi promulgado em 1993, sobre a classificação etária dos jogos de videogame, resultando num aumento de vendas e procura pelo jogo, considerado sanguinário por seus efeitos visuais, que se assimilavam a uma luta real.

\section{Estudo de caso: a série Mortal Kombat}

Para melhor compreensão do processo de desenvolvimento do vestuário nos games num recorte histórico, selecionamos Mortal Kombat em suas versões I, de 1992, II, de 1993, III de 1995, 4 de 1997 e Armageddon, de 2006, tornando explícita a evolução de representações gráficas, em maior detalhamento das peças de roupa, em combinação com o desenvolvimento tecnológico do período, Isso permitiu que, respaldado por comparações imagéticas, fosse provada efetivamente a diferenciação de trajes de um jogo para o outro, com o enriquecimento de detalhes, conforme a mais recente a versão. A lacuna temporal existente que deixamos ao selecionarmos as versões por nove anos ${ }^{3}$, entre a versão 4 (1997) e a versão Armageddon (2006), exacerba a diferença tecnológica que tal período de tempo pode simbolizar em termos de inovação, mas suficiente para não deixarmos que parte da história do jogo fique encoberta. Ressaltamos ainda que Armageddon não é a versão mais recente lançada pela produtora

\footnotetext{
${ }^{3}$ Houve outras três versões lançadas durante esse período.
} 
Midway Games, de Mortal Kombat. No mercado, encontra-se disponível a versão Mortal Kombat ${ }^{4}$, lançada em 2011.

Em 19 de Dezembro de 1995, o jornal americano New York Daily News publicou, num de seus cadernos de variedades, uma matéria sobre games que resume a série Mortal Kombat como:

The original Mortal Kombat video game debuted in 1992. Its combination of story line, character and mega-violence soon made it a hit worldwide. And the controversy engendered by its bloodgushing special effects only served to boost its popularity. ${ }^{5}$

\section{Mortal Kombat 1}

Aqui, explicamos alguns dos personagens que aparecem nas versões de Mortal Kombat (MK), citando sucintamente seu perfil. Na primeira versão do jogo, o jogador poderia optar por um dos sete personagens disponíveis: Johnny Cage (um astro de Hollywood), Kano (um mercenário e líder de um clã criminoso), Raiden (Deus do trovão e protetor do reino da terra), Liu Kang (um monge Shaolin), Scorpion (Espectro de um clã maligno de ninjas), Sub-Zero (um ninja de um clã assassino) e Sonya Blade (agente das forças especiais), além de alguns personagens especiais, que o jogador enfrentaria ao longo do jogo, mas que para jogar com eles necessitaria fazer truques, como vencer todos os adversários sem perder qualquer rodada: Reptile (um ninja que possuía técnicas de Scorpion e Sub-Zero), Goro (um monstro de quatro braços, príncipe de sua raça) e Shang Tsung (um feiticeiro maléfico).

\footnotetext{
${ }^{4}$ Popularmente chamada de Mortal Kombat 9.

5 "O videogame Mortal Kombat original foi lançado em 1992. Sua combinação de enredo, personagens e mega violência rapidamente fizeram-no um grande sucesso mundial. $E$ a polêmica engendrada por seus efeitos especiais sanguinários serviu apenas para incrementar sua popularidade" (Tradução livre do autor).
} 


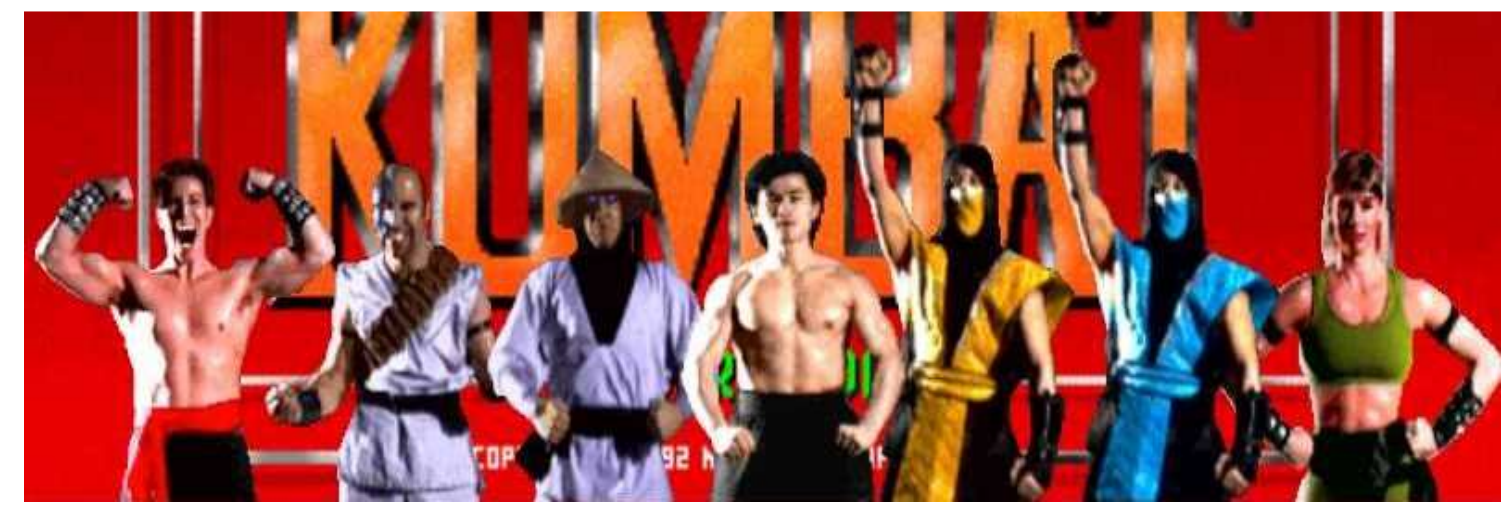

Figura 1: Personagens do jogo: Johnny Cage, Kano, Raiden, Liu Kang, Scorpion, Sub-Zero e Sonya Blade
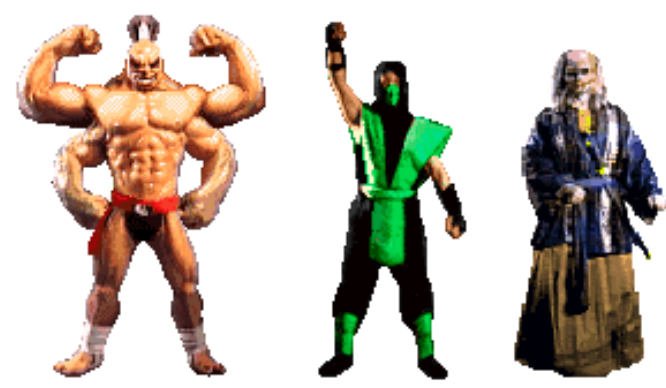

Figura 2: Personagens Secretos/Especiais: Goro, Reptile e Shang Tsung.

Um aspecto interessante de se destacar do jogo é seu pioneirismo no uso dos recursos gráficos: eram utilizadas filmagens de atores reais, já devidamente montados em seus trajes, e digitalizados para a plataforma do jogo. Recurso que tornaria o jogo mais realista e ia ao encontro com jogos do mesmo estilo da época, como seu "maior rival" Street Fighter II (SF II), que fazia ilustrações

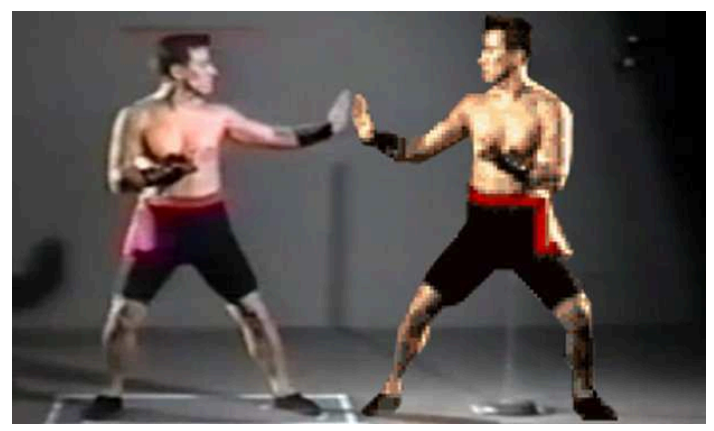

Figura 3: Ator real (esquerda) e imagem digitalizada do personagem (direita)

gráficas para representar seus personagens no jogo (conforme pode ser comparado nas figs. 3 e 4). Tal recurso possuía certas vantagens, como deixar a representação gráfica dos personagens e de suas roupas mais próxima do real, tanto na questão das áreas de luz e sombra, caimento e textura de tecidos, bem como proporções físicas da roupa e do corpo do personagem. Alguns pormenores 


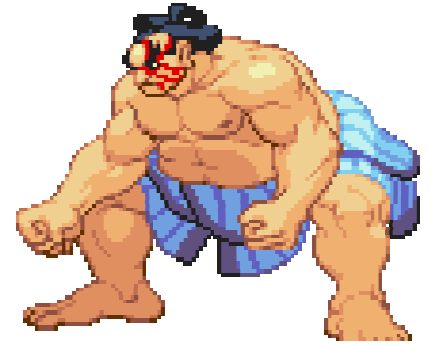

Figura 4: Personagem Honda de Street Fighter II

do uso dessa técnica devem ser lembrados: a sobreposição de imagens permitiria agregar mais dois braços ao personagem Goro, bem como a utilização de recursos de maquilagem para dar efeitos específicos à aparência dos personagens, como envelhecimento, 0 penteado atípico do personagem Goro e o rosto robotizado do personagem Kano. Entretanto, a utilização dessa técnica tirava um pouco do alto apelo da "magia" das animações utilizadas em outros jogos para crianças e adolescentes, pois tal técnica limitava de forma significativa o número de cores utilizadas em toda a parte gráfica, visto que não existiam câmeras de captação em alta-definição para filmar os atores e digitalizar as imagens. Devemos ainda citar outro recurso utilizado na parte gráfica do jogo: os ninjas do game (Sub-Zero, Scorpion e Reptile) na verdade são representações gráficas do mesmo ator, e na digitalização da fotografia, os produtores do jogo, resolveram criar personagens diferentes apenas alterando a cor da sua vestimenta já no computador, confeccionando assim um ninja azul, um verde e um amarelo. Mesmo que estes ninjas não possuíssem os mesmos comandos de golpes, qualquer diferença física é imperceptível, exatamente por se tratar da imagem do mesmo ator com a mesma roupa, apenas com mudança de cores.

Apesar da inovação tecnológica que o jogo apresentava para sua época, algumas limitações da tecnologia de jogos da época deixam suas marcas no jogo. $O$ jogo permitia que até duas pessoas jogassem ao mesmo tempo, a partir, neste caso, do modo Versus. Se, por ventura, o primeiro jogador escolhesse 0 mesmo personagem que o segundo jogador, uma falha era exposta, referente ao projeto gráfico:

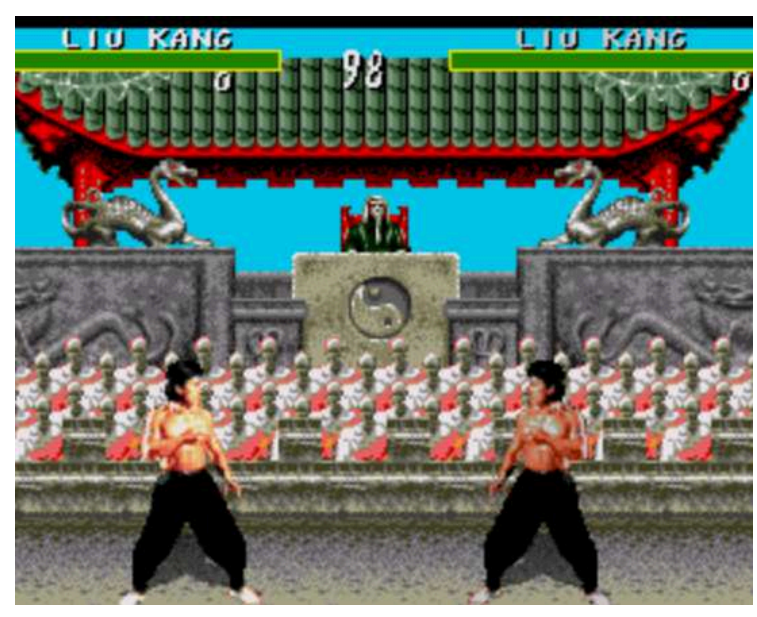

Figura 5: Modo versus com o mesmo personagem em Mortal Kombat 
a diferença do mesmo personagem na hora de jogar era que um dos personagens era escurecido, ou seja, representado graficamente com menos brilho, e não apenas sua roupa, mas todo o corpo do personagem também - a única personagem que possuía diferenciação de cor era Sonya Blade, enquanto a personagem original vestia uma roupa verde, com detalhes em branco e preto, na segunda, tinha as mesmas cores nos detalhes, diferenciando-se num tom vermelho ao invés do verde. Essa "falha" acentuava-se no personagem Scorpion, que quando escolhido por dois jogadores, o segundo apresentava um tom de amarelo muito próximo do verde, deixando-o similar ao personagem Reptile.

Por inúmeras vezes, essa parte gráfica não contemplada no projeto do jogo causava certo incômodo àquele que jogava, por facilmente confundir os personagens. E, por certa perspectiva, isso representava um aspecto em que 0 jogo poderia ser considerado inferior, por estar aquém de outros jogos, que distinguiam quando usado o mesmo personagem no player 1 e player 2, por, pelo menos, cores diferentes, como em SF II.

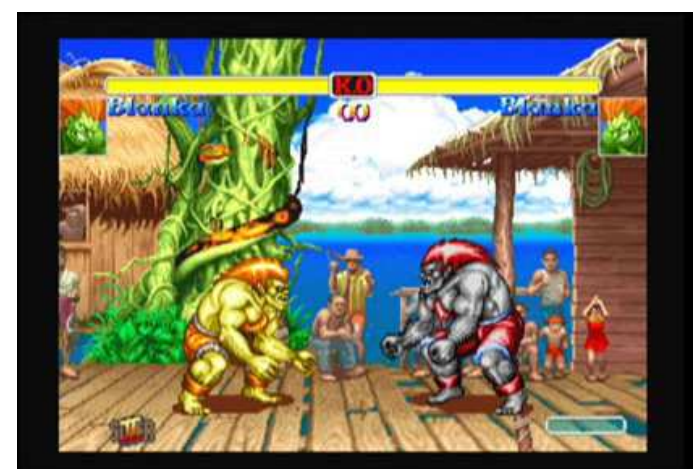

Figura 6: Modo Versus com o mesmo personagem em Street Fighter II

Ainda em MK1, vemos certas citações de estereótipos em alguns personagens, como Liu Kang, sua personalidade e seu estilo de luta remetem a Bruce Lee, sua roupa parece efetivamente ter inspirações no traje do famoso lutador, assim como os ninjas usarem máscaras que tapassem grande parte do rosto e da cabeça, como nas indumentárias de ninjas orientais, dentre outros de menor relevância. 


\section{Mortal Kombat II}

Em 1993, a Midway Games lança o novo projeto de Ed Boon e John Tobias, o Mortal Kombat II. Este projeto traz, além de resoluções gráficas mais bem acabadas, maiores detalhes $e$ acabamentos no visual dos cenários e personagens, maior jogabilidade - que significa maior número de vetores disponíveis no controle de jogo,

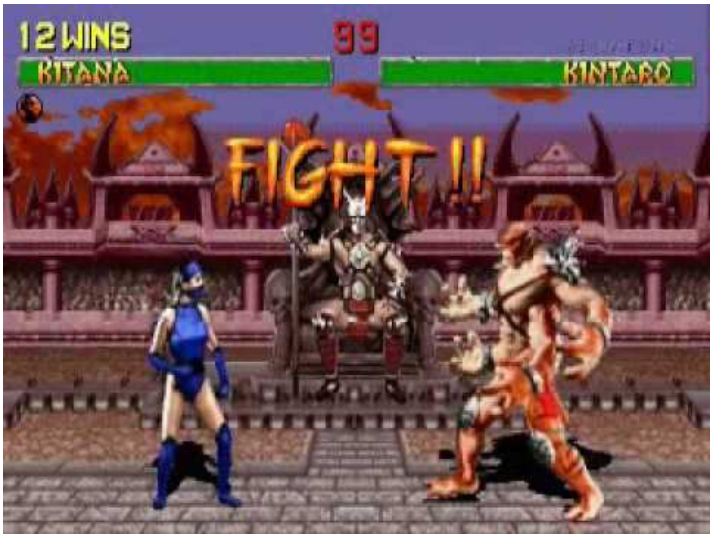

Figura 7: Kitana e Kitaro, personagens novos em MK2 correspondendo a uma melhor desenvoltura de movimentos para os personagens - e, o mais interessante neste trabalho: o enriquecimento de detalhes das roupas, bem como utilização de mais cores no mesmo traje dos personagens. Cinco personagens de $M K 1$ reaparecem nesta nova versão. $O$ feiticeiro Shang Tsung agora se torna um personagem que pode ser escolhido sem truques - com um visual bem mais jovem, pois consta na trama que o personagem recuperou a juventude -, assim como Reptile. Dois (Kano e Sonya Blade) não fazem parte do rol de guerreiros. A história do jogo conta que ambos foram presos. Além de cinco novos personagens para escolha de quem joga MKII. São eles: Baraka (um monstro híbrido com humano), Jax (um típico agente americano), Kitana (uma guerreira ninja, princesa de seu reino), Mileena (outra guerreira ninja, irmã maléfica de Kitana) e Kung Lao (um monge Shaolin). O jogo traz ainda dois personagens categorizados "chefes": Kintaro (um monstro da mesma raça que Goro, mas com um visual bem mais amedrontador - estereótipo de Goro mesclado com tigre) e Shao Kahn (o imperador impiedoso do reino do mal). Por fim, três personagens considerados secretos, que para lutar contra eles ou jogar com eles, era necessários utilização de truques: Jade (assassina ninja), Smoke (outro ninja) e Noob Saibot (espectro negro de ninja). 
Notamos, ainda, em análise comparativa, alterações visuais dos trajes de MKII com seu antecessor, evidenciando a evolução do projeto, no que se refere à indumentária. A seguir, colocamos algumas imagens do mesmo personagem na primeira versão do jogo e em sua segunda versão, anexado de sua análise imagética comparativa e comentários.
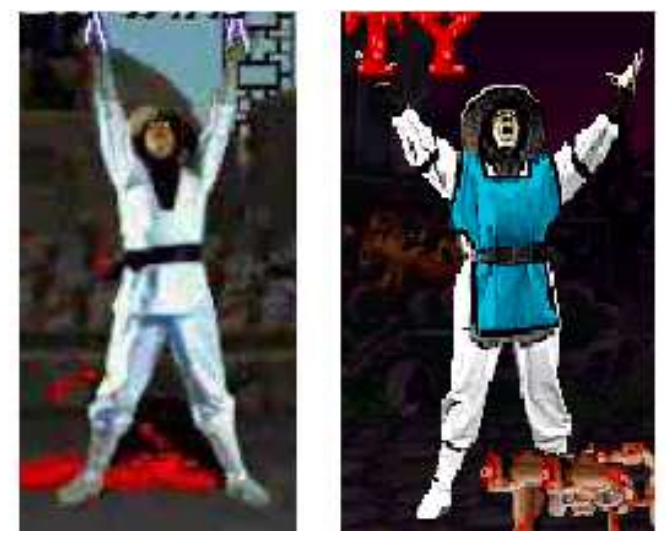

Figura 8: Raiden em MK1 e MK2

Desconsiderando as possíveis falhas de fidelidade gráfica ao da plataforma original, vemos que a versão 1 apresenta um visual mais simples, com apenas duas cores, consideradas neutras, que remetem visualmente a um traje de lutador de caratê ou judô. Enquanto na versão 2, o personagem ganha coloração em sua túnica, o azul, além de novos adereços - uma faixa preta no braço e faixas em forma de bracelete pretas nos punhos. O que torna, visualmente falando, a caracterização mais atraente, no sentido apelativo, já comentado anteriormente, por apresentar cores mais vivas. Mesmo continuando a utilizar o recurso gráfico de gravação e digitalização das imagens, os personagens agora ganham referências de animação, pela gama de cores, brilho, jogo de luz e sombra e contraste utilizados nas imagens, sem deixar de ainda representar com maior fidelidade à imagem e a formas humanas. 


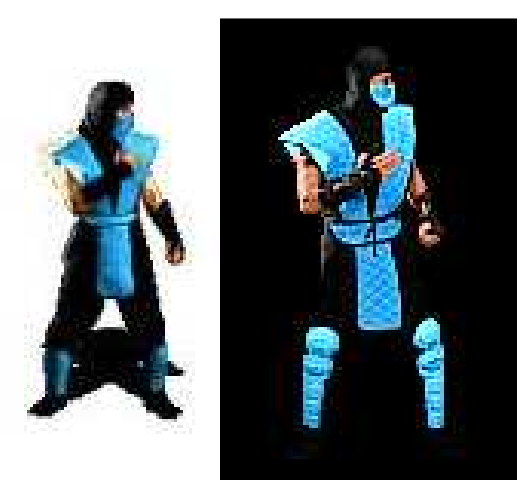

Figura 9: Sub-Zero em MK1 e MK2

Um dos personagens que aparentemente não apresenta tantas mudanças de uma versão à outra é Sub-Zero. Contudo, num olhar mais apurado conseguimos notar maior profissionalismo na confecção do traje do personagem na segunda versão, pois em ambos os casos as roupas foram feitas e usadas por atores, filmadas e digitalizadas. Isto é, frente à roupa da versão II, a do primeiro tem um aspecto menos sofisticado, pois na região da cabeça e nas caneleiras é possível observar melhores acabamentos na versão sucessora. Além disso, notamos nessa nova versão do traje, uso de luvas profissionais da arte marcial ninja e cinturão divisor mais largo, tornando o visual mais harmônico.

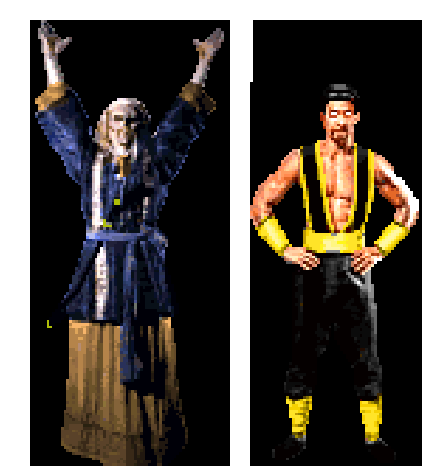

Figura 10: Shang Tsung em MK1 e MK2 


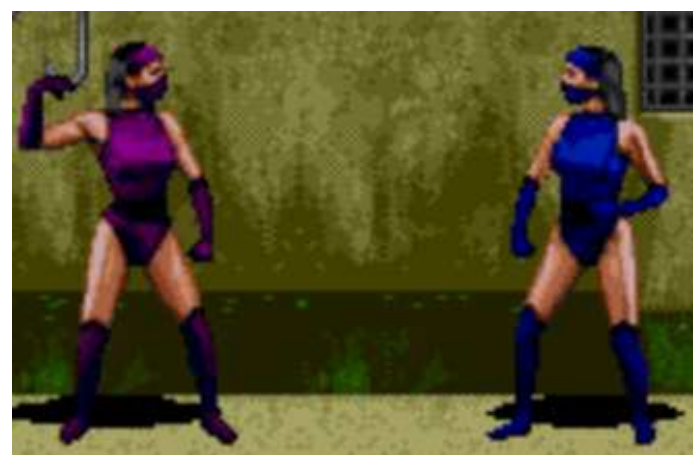

Figura 11: Personagens Mileena e Kitana

Shang Tsung, o feiticeiro, categorizado como chefe no primeiro jogo, reaparece em sua segunda versão, agora como personagem que pode ser escolhido sem necessidade de qualquer truque. Sua mudança estética e de indumentária, talvez seja a maior, ou a mais notável, entre as duas versões do game. A história do jogo nos conta que em MK2 o personagem rejuvenesceu para poder participar mais uma vez da trama criada no jogo. As mudanças visuais no personagem são muito além de um aspecto mais jovial. Sobretudo, notamos uma nova roupagem dada ao personagem, pelos criadores do jogo. Ao invés de um traje similar a um quimono oriental, em MK1, visualizamos o personagem vestido de modo completamente divergente em MK2: usando uma calça preta, braceletes, caneleiras e cinturão em tecido amarelo, um pequeno turbante em tecido preto, além de uma peça, semelhante a um suspensório, de cor preta com detalhes em amarelo. Deixando assim registrado, através da roupa, a evolução do personagem de uma versão para a outra, reeditando a roupa para tornar óbvias as mudanças comportamentais e físicas existentes no personagem.

Vale ressaltar ainda, presente no jogo, a utilização, como no primeiro jogo, de personagens que se distinguem exclusivamente pela cor da roupa: Mileena, Kitana e Jade, bem como Scorpion, Sub-Zero, Reptile e Smoke. E também, certo aprimoramento da técnica de representação gráfica: o personagem Noob Saibot, nada mais é que a representação gráfica dos ninjas, como Sub-Zero, completamente em preto, incluindo o corpo. No entanto, desta vez, os criadores se preocuparam em fazer algumas diferenciações aos personagens, além dos golpes, como em MK1: a movimentação e poses dos personagens eram divergentes entre si.

Outro fato relevante a se destacar sobre o jogo é a utilização de diferentes cores para a escolha do mesmo personagem, caso dois jogadores escolham-no (exceto 
nos personagens do clã ninja - mulheres e homens - visto que qualquer alteração cromática poderia assimilar a outro personagem, impossibilitando a criação de um novo membro do clã futuramente, em outra versão do jogo, utilizando do mesmo recurso da versão anterior do jogo: escurecimento da coloração do personagem). Pois devido pesquisas internas, os produtores notaram que a falta

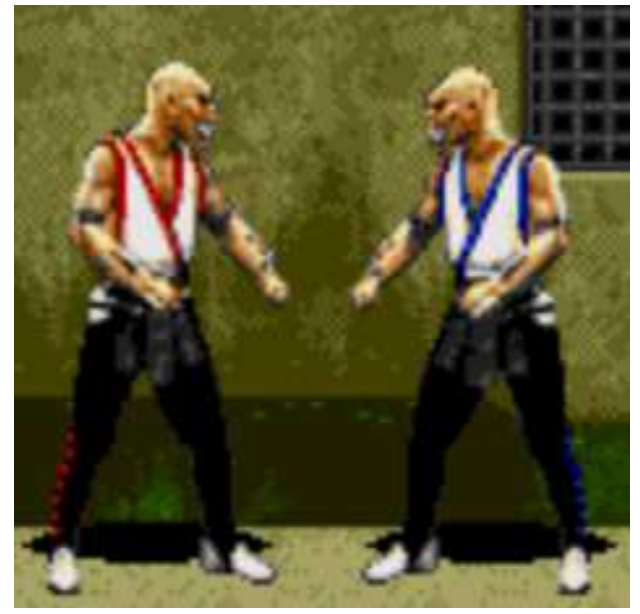

Figura 12: Personagem Baraka em modo versus de recursos para diferenciar o mesmo personagem, no caso da escolha do mesmo pelos players, causava incômodo, àqueles que jogavam.

\section{Mortal Kombat 3 e Versões}

Uma nova versão do jogo, Mortal Kombat 3, foi lançada em 1995. Desta vez, os criadores inseriram ainda mais novidades no jogo, como a utilização de seis botões no controle do

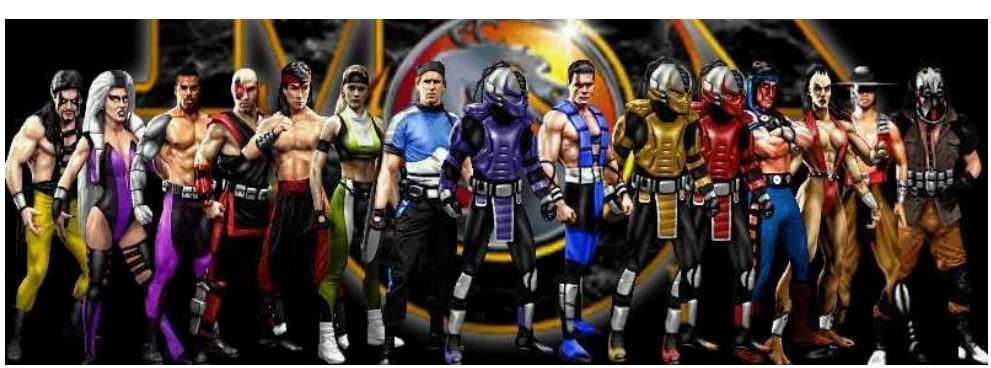

Figura 13: Personagens de Mortal Kombat 3 jogador, atendendo à demanda da utilização de novos joystick dos vídeo-games, e utilização do jogo em novas plataformas de games. Bem como, novos recursos utilizados dentro da luta - uma barra intitulada "RUN", que correspondia a um aumento de velocidade que poderia ser usado pelo personagem. $E$ ainda, novos personagens a serem escolhidos: Cyrax e Sektor (do mesmo clã ninja, em versão cibernética/robótica), Kabal (um guerreiro criminoso), Nightwolf (um nativo da tribo shaman), Sindel (rainha de um reino, ressuscitada e controlada por Shao Kahn), Sheeva (da mesma raça de Goro e Kintaro, em versão feminina) e Striker (policial americano). Os personagens que continuam no game, em relação à versão 
anterior, são: Jax (agora com braços biônicos), Kung Lao, Liu Kang, Sub-Zero (com descaracterizações de seu clã ninja), Shang Tsung, Noob Saibot e Smoke (em versão cibernética/robótica). Sonya Blade e Kano reaparecem no jogo, sendo contado pela história, que foram libertos. Os considerados chefes são: Motaro (figura que se assemelha aos centauros da mitologia grega) e novamente Shao Kahn.

As alterações na parte gráfica dos personagens, utilizando cores menos acentuadas, e o aprimoramento de digitalização de imagens, permitiram que o princípio de representação do real, instituído na versão originária do jogo, pudesse ser retomado. Visando atingir o público fiel as versões anteriores do jogo, que agora, não precisavam de apelos visuais, pois aqueles que já haviam jogado MK1 e MK2, agora já tinham mais idade, e sentiam melhor assimilação com jogos que possuíam representações gráficas mais verossímeis.

O desenvolvimento da tecnologia permitiu mudanças ainda mais acentuadas das representações gráficas das indumentárias dos personagens, em comparação à versão anterior do jogo. Na sequencia, inserimos alguns comparativos de imagens comentados acerca de tais alterações.
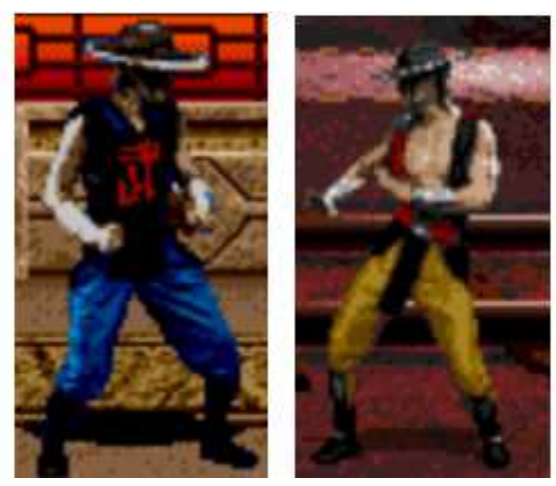

Figura 14: Personagem Kung Lao em MK2 e MK3

Notamos no personagem, assim como em outros, que os game designers criaram uma solução gráfica diferente, no que se refere à roupa, para a terceira versão do jogo: ao invés de aprimorar a roupa, foi criado um novo modelo, com maior 
complexidade visual, para o personagem. A simplicidade da indumentária de Kung Lao em MK2, com uso de uma calça e algo semelhante a uma camiseta regata foi alterado para um visual que modificou a cor de sua calça, deixou à mostra parte do tórax, acrescentou um cinto, e inseriram botas, braceletes e chapéu com melhores acabamentos, tornando a visualização estética do personagem mais homogênea, bem como, tirando o falso ar de extemporâneo (pois possuía muita proximidade às roupas orientais) que existia no seu visual anterior, e transportando-o para algo mais próximo do período em que o jogo foi criado.
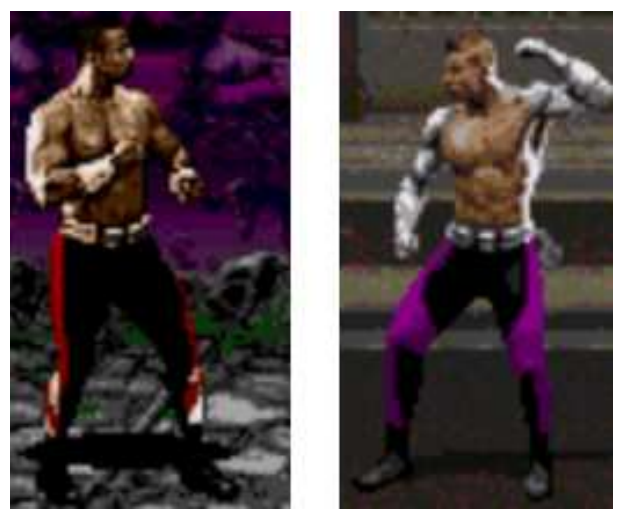

Figura 15: Personagem Jax em MK2 e MK3

Para o personagem Jax, a mudança ficou explícita apenas no acréscimo dos braços biônicos de metal. No entanto a quebra da geometrização existente na calça, na versão II do jogo, deu lugar a novo padrão em preto e roxo da calça, dando movimento à peça. $\mathrm{E}$ sob um olhar mais apurado, podemos notar que a modelagem da calça na versão mais recente, ressalta mais as formas musculares do corpo do personagem. Caracterizando a preocupação dos produtores em utilização das tecnologias do vestuário, como uma modelagem mais esportiva e adequada ao corpo. 


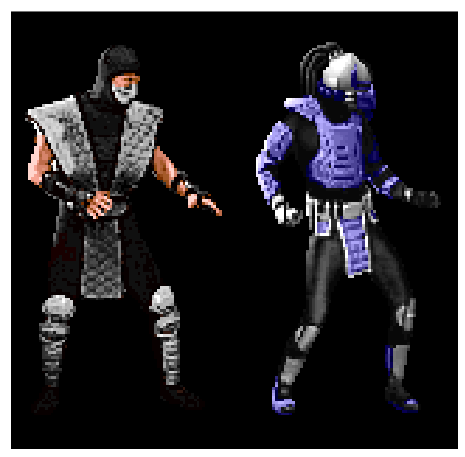

Figura 16: Personagem Smoke em MK2 e MK3

Relacionando a imagem e as vestes do personagem Smoke, em suas versões $2 \mathrm{e}$ 3 , notamos que o personagem foi reconstruído, apresentando, visualmente, pouca semelhança entre as versões. Deixando de ter visualidade de um ninja e passando a compor um robô/cyborg, com alterações também na parte cromática, do cinza ao roxo. Tais mudanças explicitavam a nova abordagem criada em MK3: contemporaneidade. No momento da criação do jogo, as pesquisas em tecnologias robóticas e computacionais encontravam-se crescentes, e para não desaperceber tal fato, o projeto do jogo possuía personagens, como Smoke, que representavam essa inovação.

Apesar de a mudança de ninja para robô não ter caído no gosto dos fãs, os criadores resolveram, em versão paralela do jogo (Ultimate Mortal Kombat 3 e Mortal Kombat Trigoly), resgatar o clã dos ninjas, considerando assim que Smoke de MK3, não seria o mesmo de MK2, e sim um novo personagem, Smoke Robot.

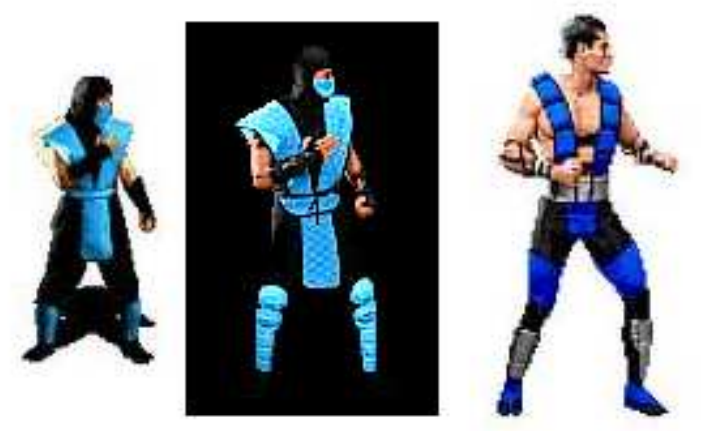

Figura 17: Sub-Zero em MK1, 2 e 3

A evolução do ninja Sub-Zero, que de MK1 para MK2, parecia sucinta, torna-se, na versão 3 , mais efetiva. Deixando de portar um traje com alta semelhança a um 
ninja, ele aparecia agora, sem máscara, com um adereço similar a um suspensório, detalhes mais bem acabados, quebra da geometrização das formas e linhas da roupa, modelagem mais anatômica e a manutenção da sua cor símbolo, o azul (mesmo que em tom diferente).

É interessante destacar que novamente foi utilizado o recurso de criação de novos personagens baseado no template de um personagem já existente, com a alteração da cor para a criação de um novo. Neste game, Smoke, Cyrax e Sektor são do mesmo clã ninja já existente, mas em versão cibernética/robótica, com apenas diferenças cromáticas. Também, nas versões paralelas, foram mantidos os clãs ninjas masculinos e femininos, com distinção de cores entre os personagens.

Sobre o aspecto considerado falho nas versões anteriores, a distinção do mesmo personagem escolhido por dois jogadores, em MK3 parece ser completamente solucionada.

Os personagens possuem

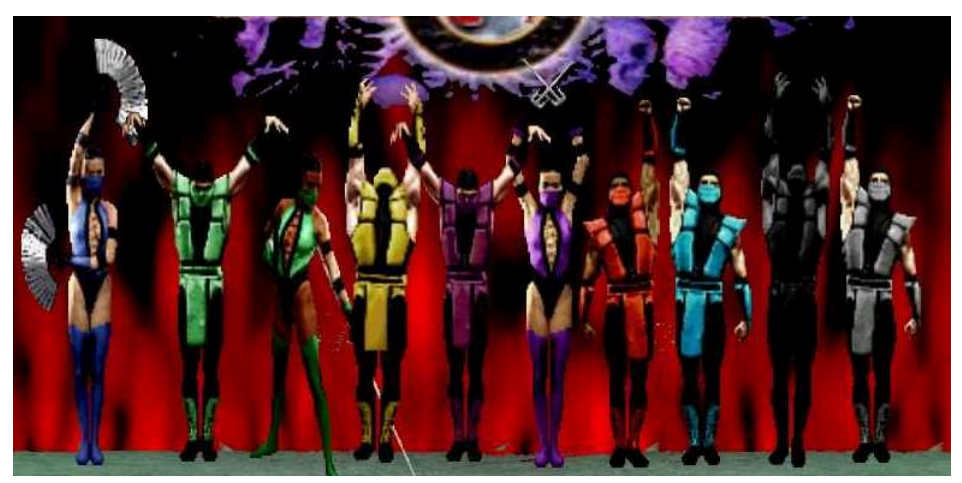

Figura 18: Guerreiros do clã ninja em Ultimate MK3 conjuntos cromáticos diferentes, quando escolhido o mesmo pelos players, inclusive o ninja Sub-Zero, que ao invés de escurecê-lo, os produtores colocaram outra tonalidade de azul em sua indumentária, sem assim, descaracterizá-lo.

De um modo geral, podemos dizer que a abordagem dos autores do jogo a nova versão foi, sem sombra de dúvidas, a contemporaneidade. Em contrapartida às tentativas de atmosfera extemporânea criada nas versões anteriores, que para muitos críticos de games, era fictícia, pois muito se assimilava com a cultura oriental (China e Japão), a nova versão assume o momento em que o jogo fora produzido. Exposta por personagens de estereótipo americano e cenários de grandes metrópoles, a abordagem ocidental foi mesclada com a essência mítica, 
já tradicional nos jogos de Mortal Kombat, de mundos e reinos paralelos e criaturas não humanas. Pois a própria história do jogo contava, que no momento retratado da terceira versão do jogo, estes universos se uniriam para que um torneio pudesse ocorrer.

\section{Mortal Kombat 4}

Em 1997, a quarta versão da série MK é lançada: Mortal Kombat 4. Diferente das versões anteriores em inúmeros aspectos, o mais importante foi a mudança de representação gráfica escolhida pelos autores. Deixando de ser por digitalização de imagens de atores reais, nesta versão do jogo, os criadores resolvem capitanear uma vertente mais contemporânea para o design gráfico do jogo: computação gráfica em 3D.

Mesmo que os personagens aparentassem ter volume nas versões anteriores, existiam apenas dois planos; um onde os personagens se encontravam; e outro onde se localizava o cenário. Na versão 4 , o jogo possuía mais um plano, a profundidade, que criava integração harmônica entre o plano dos personagens e do cenário, dando visualidade a uma perspectiva em que os jogadores e os cenários pudessem ser vistos por ângulos diferentes.

Este recurso, já adotado desde 1993, pelo pioneiro Virtua Fighter, em 1994, por Tekken - o mais famoso do gênero em 3D - e em 1996, por seu maior concorrente, Street Fighter, na versão $E X$, fora utilizado apenas na quarta versão do game, pelos produtores considerarem o método imperfeito, até então: suas representações

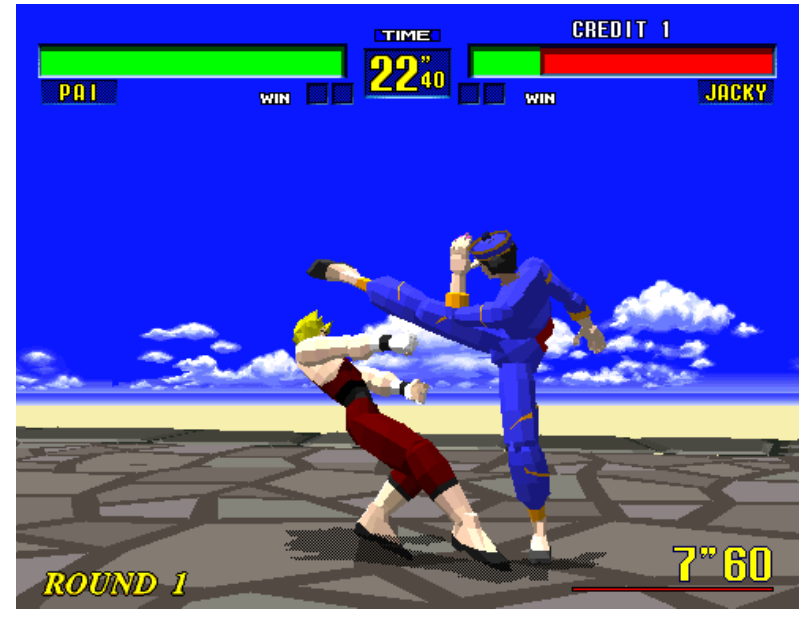

Figura 19: Virtua Fighter, de 1993 
possuírem vetorização da figura humana, tornando-a angular ao invés de curva, por sua base poligonal gráfica. Com o desenvolvimento de novos softwares e aprimoramento do uso da técnica 3D, os criadores e a distribuidora fizeram seu primeiro experimento do recurso em MK4.

Dentre os personagens disponíveis, os novos são: Fujin (deus do vento), Jarek (representante do clã de, então assassinado, Kano), Kai (monge amigo de Liu Kang), Quan Chi (um misterioso feiticeiro maligno), Reiko (um general maléfico), Shinnok (um dos três deuses anciãos, considerado chefe do

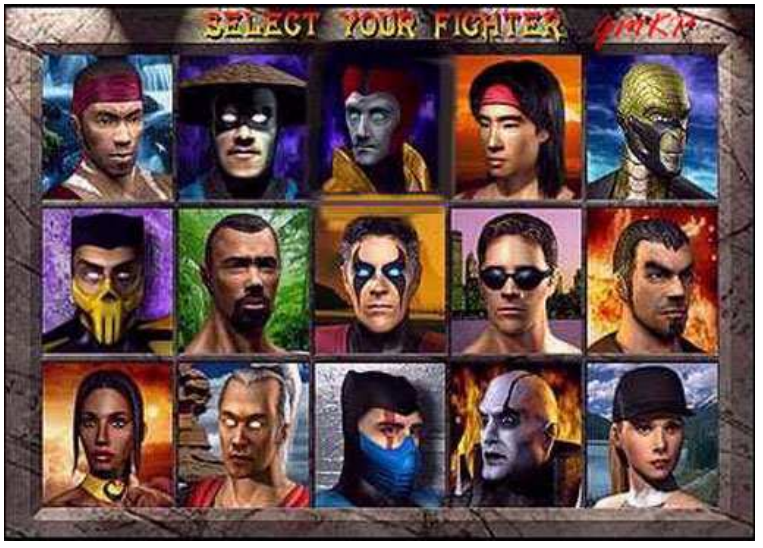

Figura 20: Cartela de seleção de personagens em MK4 jogo), Meat (personagem sem pele) e Tanya (traidora de seu reino). Os que ressurgem são: Liu Kang, Jax, Johnny Cage, Raiden, Reptile, Scorpion, Sonya Blade, Goro, Noob Saibot e Sub-Zero. A decisão de escolha dos personagens foi difícil, segundo os criadores (Apud. WINTER), pelo grande número de personagens que até então faziam parte do jogo. Entretanto, a decisão se deu pelos personagens centrais e os de maior significância na história, até então, e por aqueles de maior apelo popular, como Sub-Zero e Scorpion.

Desta vez, não por conta da utilização de um recurso gráfico diferente, mas por vários fatores - dentre eles, a abordagem e a história do jogo -, a roupa dos personagens apresentadas possuíam imensas diferenças frente às versões anteriores. Foram selecionados alguns personagens, para análise e comparação, vista a seguir. 


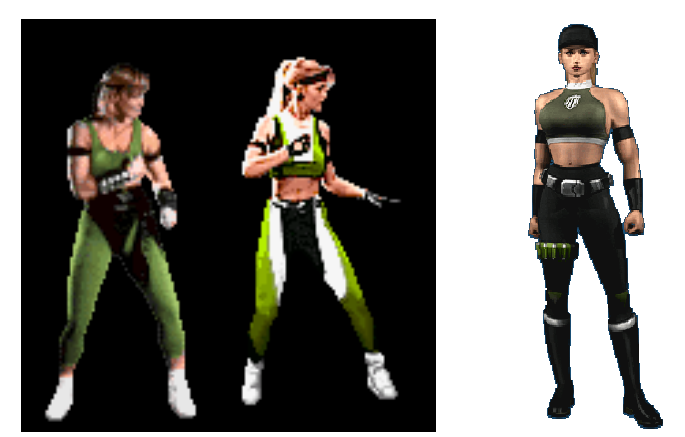

Figura 21: Personagem Sonya Blade em MK1, MK3 e MK4

Observamos que para a versão 4 do game, Sonya Blade apresenta linhas (na roupa) mais sensuais, mantendo o abdômen à mostra, como na versão MK3, decotando mais a cava da blusa e ajustando a modelagem da calça e da blusa anatomicamente. Também, a troca das luvas por faixas de tecido como braceletes, acréscimo de um adereço na perna, mudança de tênis para botas coturno e alteração da faixa na cabeça por um boné, remetendo às origens da personagem - comando das forças especiais. E ainda, reeditando a tonalidade do verde da roupa, tornando o visual mais sóbrio. Em síntese, visualizamos a personagem fazendo jus, por sua indumentária no quarto jogo, à história contada no game, pelos criadores.
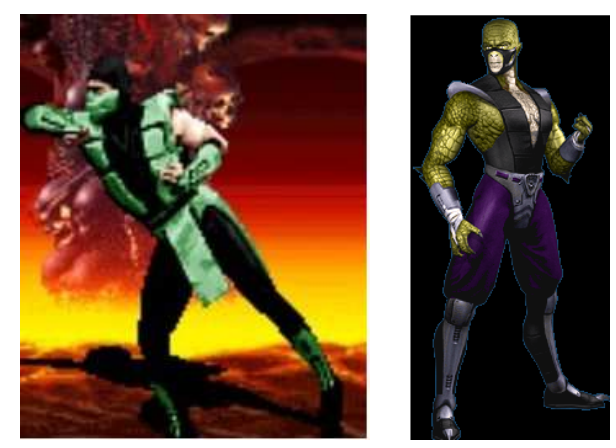

Figura 22: Personagem Reptile em MK3 e MK4

Para a versão em 3D do jogo eletrônico, o personagem Reptile embrandece o visual estereotipado do clã ninja, deixando apenas leves nuances, como um adereço no rosto similar a uma máscara ninja, e respeitando, igualmente à Sonya, sua origem histórica, um guerreiro representante de uma etnia híbrida de humanos com reptilianos. Houve uma repaginação na estrutura do vestuário do personagem, portando na quarta versão um colete preto, calça roxa, com ombreiras, caneleiras, braceletes e cinturão metalizados. E para não descaracterizar completamente 0 personagem, manteve-se a coloração 
esverdeada no visual, entretanto foi migrado da roupa à pele (que agora possui aspecto de réptil).
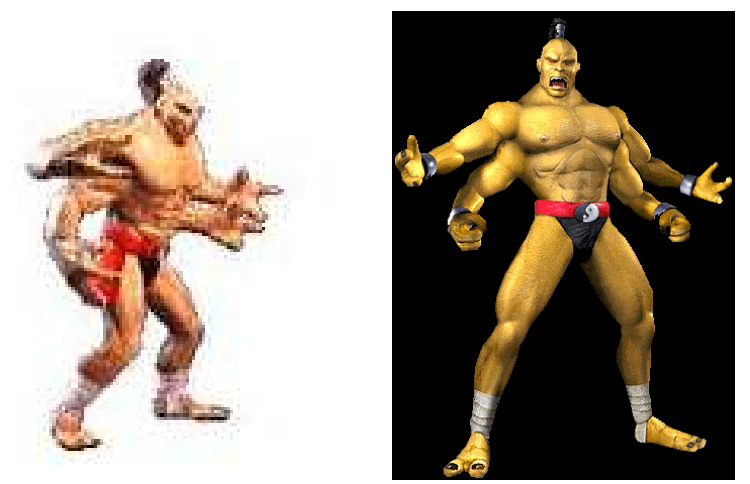

Figura 23: Personagem Goro em MK1 e MK4

Um caso atípico dentre todas as versões pode ser visto no personagem Goro. Suas mudanças visuais encontram-se completamente em torno de técnica de representação visual gráfica. Não houve mudança, ou qualquer alteração na peça de roupa, nem nos adereços nos punhos e tornozelos. Parcialmente a razão disso deve-se ao personagem usar apenas um sungão como figurino, e seu apelo visual estar mais inerente ao físico/músculos. Outro motivo para tal manutenção de visual é o apelo da imagem do personagem, cuja aparição causou imensa nostalgia e agrado, frente aos fãs - pois o personagem havia aparecido apenas na primeira versão do jogo.

Em linhas gerais, podemos afirmar que Mortal Kombat 4 iniciou a série de jogos no gênero mais moderno dos games, o 3D. Se por um lado isso desagradou os fãs mais antigos do jogo, por romper com um projeto gráfico singular, existente nas versões anteriores, com utilização de atores reais, por outro, permitiu com que o visual do jogo adentrasse no tridimensional, e de um modo geral ajudou com que o projeto gráfico do jogo fosse aprimorado e melhor acabado, criando soluções cada vez mais verossímeis nas versões posteriores, pela utilização de softwares de computação gráfica ainda mais avançados. Vale ressaltar ainda que 
nesta versão fora novamente utilizada a distinção, quando escolhido o mesmo personagem para ambos os players, por cores da indumentária.

Catorze anos após o lançamento do primeiro Mortal Kombat, depois de várias versões, chega aos videogames Mortal Kombat Armageddon, considerado cronologicamente - vide história do jogo - o capítulo final da série.

Com alta performance de interatividade com o jogador, repleto de novos recursos que expandem as modalidades de batalhas, a versão Armageddon contempla com muita propriedade as demandas mercadológicas em torno de games do gênero luta. E a indumentária consagra sua função, representando uma evolução perante seu significado às versões pioneiras.

\section{Mortal Kombat Armageddon}

Destacamos que ao longo desse recorte histórico (de 1991 a 2006), o vestuário deixou de ser decorativo e tornou-se um dos elementos fundamentais da interatividade com o jogador. Em MK Armageddon o jogador, além de ter duas opções de roupa para escolher de cada personagem, pode ainda customizar completamente a indumentária e a imagem de seu personagem predileto. $\mathrm{O}$ jogo utilizou um recurso muito atraente para que o jogador fosse estimulado a customizar a roupa de seu personagem, ou mesmo criar um novo personagem; habilitar novas peças de roupa e adereços conforme o desempenho do jogador ao jogar. Isto é, conforme a desenvoltura durante o game, acumulava-se certa quantia de

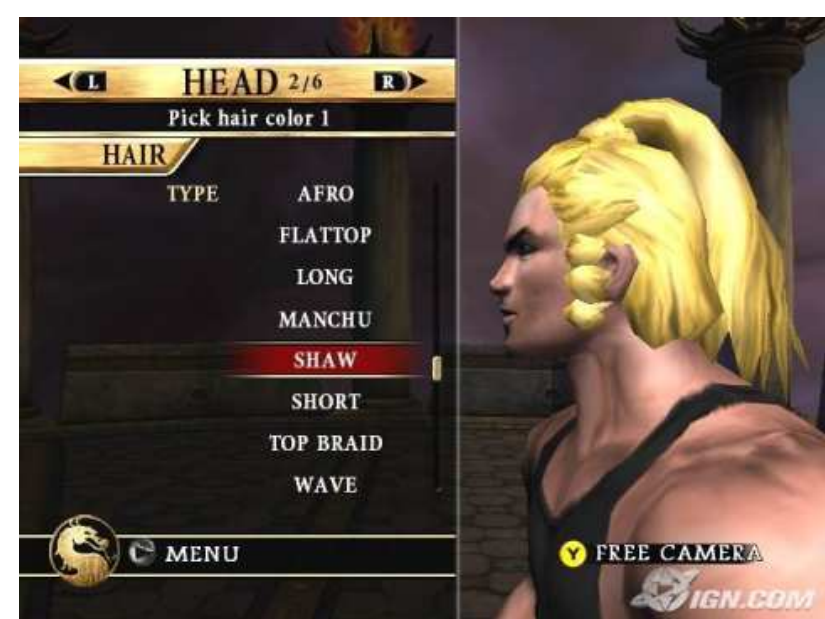

Figura 24: Menu de montagem de personagem 
pontos que poderiam ser trocados por peças de roupa ou acessórios, como calças, saias, blusas, armaduras, braceletes, luvas, chapéus, cintos, faixas, entre outros itens.

$\mathrm{Na}$ verdade o jogo apenas integrou ao seu software um utilitário que há alguns anos já havia sendo executado em outros games, como em Tekken 3, onde os personagens possuíam roupas secretas, liberadas conforme acumulo de vitórias. No entanto não devemos desprezar o recurso adotado na versão Armageddon, visto que não se trata de uma simples cópia do utilitário, mas sim um aperfeiçoamento, pois nesta versão do jogo todo o conjunto visual do personagem poderia ser alterado, incluindo, além da roupa, corte de cabelo, aplicação da maquilagem, tonalidade de pele e etc. Bem como a criação independente de um personagem novo.

Outra solução interessante que os criadores do jogo trouxeram para a versão de 2006 foi a oferta de personagens: todos os personagens que já haviam aparecido nas versões anteriores do game (desde Mortal Kombat 1) estavam disponíveis para escolha na cartela de personagens, sem exceção, e sem necessidade de códigos ou truques para a sua liberação. Além disso, novos personagens foram acrescentados a essa cartela. A história do game conta que cronologicamente, Mortal Kombat Armageddon ocorre num momento de colapso temporal entre todos os mundos paralelos e o reino da Terra. E, portanto, todos os personagens encontram-se presentes. Satisfazendo assim a todo e qualquer fã de personagem, mesmo dos mais obscuros e não apelativos, e contando um momento histórico aos admiradores do jogo.

Selecionamos algumas análises imagéticas de comparação de vestuário, explicitando suas devidas evoluções. 

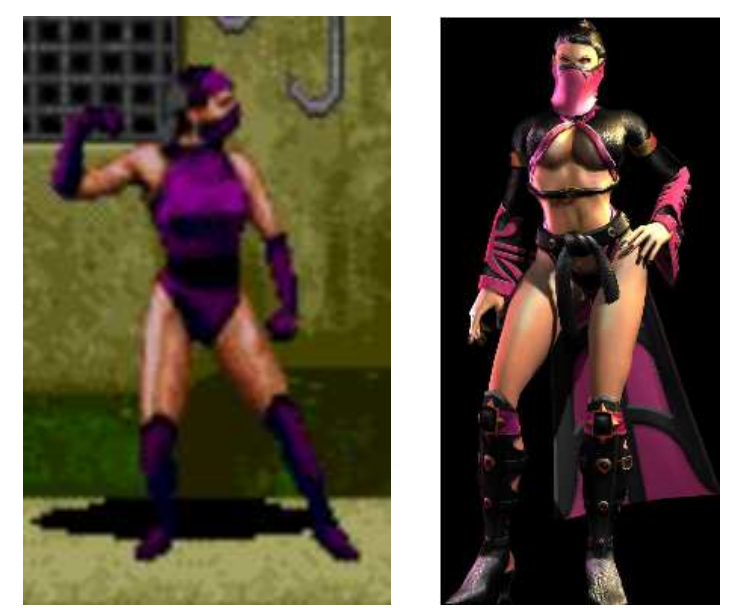

Figura 25: Personagem Mileena em MK2 e MK Armageddon

A personagem Mileena é um exemplo típico e claro da evolução de indumentária existente através das versões do jogo. E contemplando os estereótipos desejados aos games, pelos jogadores, ao longo do tempo. Em MK 2, de 1993, onde as artes marciais de origem oriental atraiam a atenção daqueles que se interessavam pelos jogos do gênero luta, e em MK Armageddon, de 2006, onde a figura feminina que mesclava sensualidade e força/poder tornava-se atraente aos que jogavam.

Mesmo com mudanças de comportamento no visual da personagem não devemos afirmar que os produtores do jogo deturparam o perfil comportamental da personagem. Mantiveram-no e alteraram apenas a abordagem dada à imagem da personagem, sobretudo nas vestes. Para compreendermos, devemos observar que elementos do vestuário foram mantidos, da figura original, mesmo passando por várias versões do jogo, como: cintura marcada por uma faixa, botas, máscara ninja, e o aspecto mais marcante de cada personagem na série de jogos, a cor da roupa.

Destacamos ainda, que ao longo das versões do jogo, os criadores inseriram o desenvolvimento de modelagem das peças de roupa, caimento e textura dos tecidos, relevos e aviamentos dispostos na indumentária, cartelas cromáticas mais ousadas, bem como design de estamparia - visível nas mangas da blusa de Mileena na versão Armageddon. 


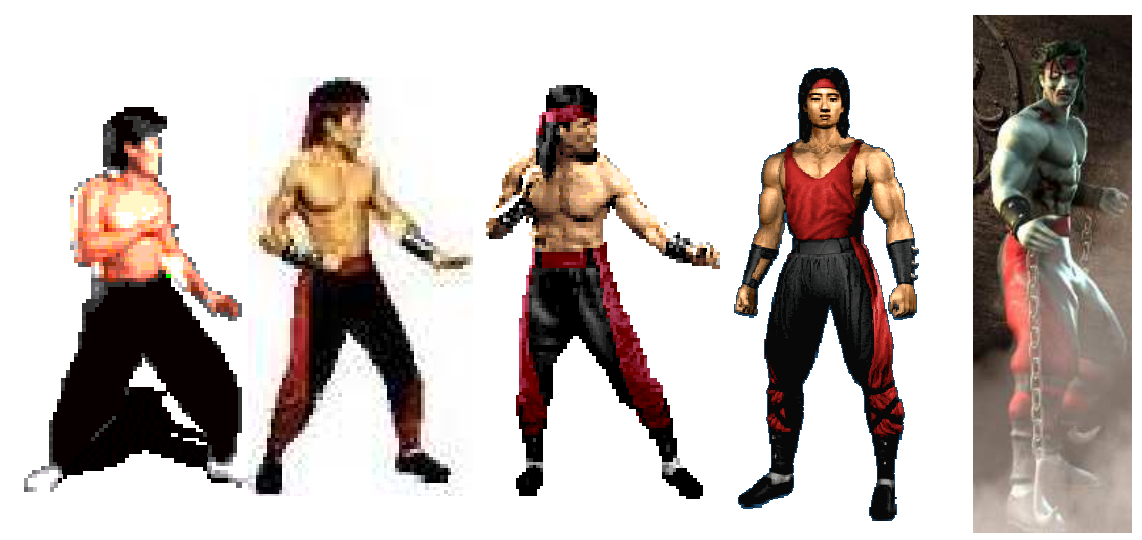

Figura 26: Personagem Liu Kang em MK1, 2, 3, 4 e Armageddon

Devemos ainda ressaltar a evolução da representação de vestuário do personagem central do jogo: Liu Kang. Assim como o já comentado caso do personagem Goro, Liu Kang é um personagem com certo grau de dificuldade de, mesmo as mínimas, alterações. Em certa perspectiva, averiguamos que a maior parte dos fãs de jogos eletrônicos do gênero luta é bastante conservadora no que diz respeito à imagem dos personagens principais. Uma breve análise das imagens dos personagens principais de jogos do estilo mostra que as mudanças, quando existentes, no vestuário dos personagens com maior importância é bastante limitada - pois este recurso permite que o jogo seja facilmente reconhecível a quem joga, nos seus personagens centrais, tal como um filme com continuação, que mantém os personagens principais. No caso de Liu Kang, a maior alteração fora da primeira à segunda versão do game, onde o personagem ganha uma faixa vermelha na cabeça, insere a mesma cor na calça, muda a cor do sapato para preto e ganha braceletes. Dalí em diante, pouco se alterou em sua roupa. Com exceção da versão 4, onde o personagem ganhou uma camiseta regata, fato que foi refutado pelos fãs, levando os game designers a retirarem-na, nas versões seguintes, segundo BOBANY (2008).

A maior significância de alteração na roupa do monge Shaolin não está perceptível (com facilidade) visualmente. Trata-se de uma questão de Design, adotado para todos os personagens ao longo das versões do jogo. Ou seja, preocupação com representação gráfica em soluções técnicas das roupas: 
modelagem, caimento de tecido, relevo, aviamentos e adequação da combinação de cores.

O que podemos comentar acerca da última versão da roupa, em específico, é a adição de correntes às pulseiras, pois tal adereço traria maior simbolismo ao momento do personagem, no caso, ressuscitado. As correntes trazem a impressão de que o personagem estaria condenado, e de fato, conforme a história, o personagem estava condenado ao vale da morte, quando foi resgatado para lutar no último capítulo da saga Mortal Kombat. Seu estado de putrefação pode ser notado pelo aspecto da pele, que não foi abordado na indumentária, para não descaracterizar suas tonalidades cromáticas já consagradas ao longo da série do jogo.

\section{Conclusão}

De um modo geral, podemos dizer que o último jogo da série MK, mostra com clareza e coerência o interesse que surgiu, ao longo de suas versões, dos criadores em atrair o olhar, cada vez mais crítico, daqueles que jogam. Pois atualmente, videogame não pode ser considerado uma máquina de entretenimento de crianças e adolescentes do sexo masculino, pois expandiu seu público em idade, classe social e gênero. $\mathrm{E}$ uma das áreas de interesse de quem joga o game é como os criadores dão soluções técnicas criativas para a representação gráfica da indumentária de cada personagem, e como ela evolui de uma versão à próxima, e em seu contexto geral. Os criadores jamais poderiam inserir peças de roupas aos personagens conforme as tendências do momento em que o jogo era montado, pois isso limitaria a temporalidade com que as pessoas pudessem se entreter ao jogar o game, causando a sensação, após um período de tempo, de que o jogo seria típico de uma época, por seus personagens enaltecerem isso, o que sempre foi evitado pela maioria dos game designers ao longo da recente história do videogame. Também não poderiam mudar aleatoriamente as vestimentas de seus personagens, pois isso 
descaracterizaria qualquer linearidade no perfil psicológico e comportamental do personagem, tornando difícil a assimilação do mesmo de uma versão à outra.

Portanto utilizamos como estudo de caso a série Mortal Kombat, por enxergarmos que seus criadores realizaram sempre um projeto com extremo cuidado e alto detalhamento. No que diz respeito a pensar no design do jogo, sobretudo na indumentária, o trabalho de criação e desenvolvimento pode ser considerado profissional e bem elaborado, conforme expusemos neste artigo.

\section{A DRESSING ANALYSIS IN MORTAL KOMBAT: HISTORICAL AND DEVELOPMENT}

ABSTRACT: This article seeks to analyze the evolution of the image of the characters in the electronic games, most of all in their dressing, with focus of study in Mortal Kombat, in its version 1 , 2, 3, 4 and Armageddon, respectively released in 1992, 1993, 1995, 1997 and 2006. At this initiative, we had the opportunity to register the contemporaneously cultural and recreational importance that the games have on society. Moreover, we demonstrate that the developed new technology and tools, in the referred game, recently incorporate, aptly, some aspects of the human behavior in dressing. Showing the concerning of the creators of the game in attempt and overcome the player's expectation, referring to the character's clothing. Throughout the period of time selected we noticed that were applied interactive characteristics, gameplay and graphic representation improvements, design's principles and more functionality, making the game each time more sophisticated.

KEYWORDS: Mortal Kombat. Game Design. Costumes. Apperance Design.

\section{Referências:}

BETTON, Gerard. Estética do cinema. 1 ed. São Paulo: Martins Fonte, 1987. $122 p$.

BOBANY, Arthur. Videogame Arte. 1 ed. Teresópolis, Rio de Janeiro: Novas Ideias, 2008. 192p.

CALDERIN, Jay. Form, fit, and fashion: all the details fashion designers need to know but can never find. Beverly: Rockport Publisher, 2009. 288p.

CARDOSO, Rafael. Uma introdução à história do Design. São Paulo: Editora Blucher, 2008. 276p.

CHIERICHETTI, David. Edith Head: The Life and Times of Hollywood's Celebrated Costume Designer. New York: HarperCollins, 2003. 193 p. 
CLUA, E; BITTENCOURT, J. Desenvolvimento de Jogos 3D: Concepção, Design e Programação. In: Anais da XXIV Jornada de Atualização em Informática do Congresso da Sociedade Brasileira de Computação, p. 1313-1356. São Leopoldo: 2005.

DESENVOLVIMENTO DE JOGOS ELETRÔNICOS. Disponível em: $<$ http://pt.wikipedia.org/wiki/Desenvolvimento de jogos eletr\%C3\%B4nicos >.

Acesso em 3 mai. 2012.

DOMINGUES, Diana (Org.). Arte, Ciência e Tecnologia: passado, presente e desafios. São Paulo: Editora UNESP, 2009. 570p.

FERREIRA, Aleteia; VIEIRA, Josiany Fiedler; RIGO, Paula. As superpoderosas dos games: a comunicação feminina na cibercultura. In: Seminário de games, comunicação e tecnologia. 14 p. Novo Hamburgo: 2006.

FIGURINO. Disponível em: <http://pt.wikipedia.org/wiki/Figurino>. Acesso em: 29 abr. 2012.

GAMES. New York Daily News. In: Varieties. New York: 1995.

GHISLERI, Janice. Linguagem do vestuário Teatral. Disponível em: <http://ecojane.wordpress.com/2010/10/21/linguagem-do-vestuario-teatral/>. Acesso em: 9 mai. 2012.

HISTORY of video game. Disponível em: <http://en.wikipedia.org/wiki/History_of_video_game>. Acesso em: 9 mai. 2012.

LEITE, Adriana Sampaio; GUERRA, Lisette. Figurino, uma experiência na televisão. 1 ed. Rio de Janeiro: Paz e Terra, 2002. 228p.

LEVENTON, Melissa. A história ilustrada do vestuário: um estudo da indumentária, do Egito antigo ao final do século XIX, com ilustrações dos mestres Auguste Recinet e Friedrich Hottenroth. São Paulo: Publifolha, 2009. 352p.

LIPOVETSKY, Gilles. O império do efêmero: a moda e seu destino nas sociedades modernas. São Paulo: Companhia das letras, 2009. 347p.

MARTIN, Marcel. A linguagem cinematográfica. São Paulo: Brasiliense, 2007. $237 \mathrm{p}$.

MENDONÇA, Miriam da Costa Manso Moreira. O reflexo no espelho: o vestuário como linguagem artística e simbólica. 1 ed. Goiânia: CEGRAF/UFG, 2006. 260 p.

MORENO, Carlos Alexandre de Carvalho; OLIVEIRA, Janete. Cosplay e a visão da cultura japonesa no Brasil. In: XXXII Congresso Brasileiro de Ciências da Comunicação. 13 p. Rio de Janeiro: 2008. 
MORTAL KOMBAT [2011 video game]. Disponível em: <http://en.wikipedia.org/wiki/Mortal_Kombat_(2011_video_game)>. Acesso em: 1 mai. 2012.

MORTAL KOMBAT [Video game]. Disponível em: <http://en.wikipedia.org/wiki/Mortal_Kombat>. Acesso em: 1 mai. 2012.

MORTAL KOMBAT 3. Disponível em: <http://en.wikipedia.org/wiki/Mortal_Kombat_3>. Acesso em: 1 mai. 2012.

MORTAL KOMBAT 4.4 Disponível em: <http://en.wikipedia.org/wiki/Mortal_Kombat_4>. Acesso em: 1 mai. 2012.

MORTAL KOMBAT ARMAGEDDON. Disponível em: <http://en.wikipedia.org/wiki/Mortal_Kombat:_Armageddon>. Acesso em: 1 mai. 2012.

MORTAL KOMBAT II. Disponível em: <http://en.wikipedia.org/wiki/Mortal_Kombat_Il>. Acesso em: 1 mai. 2012.

MORTAL KOMBAT. Disponível em: <http://en.wikipedia.org/wiki/Mortal_Kombat>. Acessado em: 1 mai. 2012.

MORTAL KOMBAT. Disponível em: <http://www.themortalkombat.com/>. Acesso em 1 mai. 2012.

NAZARIO, Luiz, FRANCA, Patrícia (Org.). Concepções contemporâneas de arte. Belo Horizonte: Editora UFMG, 2006. 350p.

NYEMEYER, Lucy. Elementos de semiótica aplicados ao design. $4^{\mathrm{a}}$ tiragem. Rio de Janeiro: 2AB, 2010. 80p.

PERUCIA, Alexandre. Desenvolvimento de jogos eletrônicos. 2 ed. Rio de Janeiro: Novatec, 2007. 320 p.

PESQUISA Mostra Número De Videogames Nos EUA. Disponível em <http://fansitenews.com.br/2010/03/31/pesquisa-mostra-numero-de-videogamesnos-eua/>. Acesso em: 13 abr. 2012.

STREET FIGHTER II. Disponível em: <http://en.wikipedia.org/wiki/Street_Fighter_Il>. Acesso em: 5 mai. 2012.

TERCEIRA EVOLUÇÃO DOS JOGOS ELETRÔNICOS. Disponível em: $<$ http://www.angelfire.com/art2/xandones/pagina6.html>. Acesso em: 14 mai. 2012. 
VAZ, Adriana. O design de aparência de atores e a comunicação em cena. 2008. 187 p. São Paulo: 2008.

VIDEOGAME.

Disponível

em:

<http://pt.wikipedia.org/wiki/Jogos_eletr\%C3\%B4nicos>. Acesso em: 30 abr. 2012.

VÍDEO GAME É A 4a aTIVIDADE MAIS POPULAR ENTRE CRIANÇAS. Disponível em: <http://www.espacogames.com/video-game-e-a-4a-atividademais-popular-entre-estas-criancas/4466/>. Acesso em: 13 abr. 2012.

WINTER, David. The site of the first videogame. Disponível em: <http://www.pong-story.com/intro.htm>. Acesso em: 18 abr. 2012.

Texto recebido em 13/08/2013. 